\title{
Exercise Considerations
}

\section{Charles Maack*}

\section{US Too International Inc, USA}

The following are a sampling of exercise considerations compiled from various resources. They certainly are not all encompassing or all inclusive. The extent one exercises should be determined by their health and physical capabilities. Most certainly discuss your plan with your health care provider and start very slowly until comfortable with any exercise, then increase dependent on continued comfort. The saying "no pain, no gain" can be used with reservations/limitations. Light "pain discomfort" can be anticipated, since when embarking on an exercise regimen following little previous deliberate exercise one will likely experience some pain discomfort. When this occurs, it is an indication to either lighten up or not exceed that level of exercise until the body parts have acclimated to the exercise and that discomfort disappears.

You are often more encouraged if you find someone to work with you. For the Heart patient, MedlinePlus provides several exercise considerations; please open and review the following [1].

This from the Cleveland Clinic:

\section{Exercise guidelines:}

- Every patient should consult with his or her health care provider before beginning an exercise program.

- A good exercise program starts slowly, allowing your body time to adjust.

- Keep a regular exercise schedule -- exercise at least three times a week.

- Even more dangerous than not exercising at all is exercising only occasionally.

- The right kind of exercise never makes you feel sore, stiff, or exhausted. If you experience soreness, stiffness, exhaustion, or feel out of breath as a result of your exercise, you are overdoing it.

- Most exercises are safe, as long as you exercise with caution and you don't overdo it. The safest and most productive activities are swimming, brisk walking, indoor stationary cycling, and low-impact aerobics (taught by a certified instructor). These activities carry little risk of injury and benefit your entire body.

Similar exercises are explained for maintaining good health in this paper shown for women, but works as well for men [2]. And, of course, you can access the internet and find many exercise routines. I believe it important to recognize your strength and age limitations and to begin these exercises lightly, slowly, and with caution so as not to over-extend or cause yourself harm.

This from Karen L. Swartz, M.D., of Johns Hopkins

Exercise tip 1: Exercise now...and again.

Research shows that a 10-minute walk can improve your mood for two hours. Another study demonstrates that 10 minutes of pedaling on a stationery bike is enough to make you feel better, at least temporarily. The key to sustaining mood benefits is to exercise regularly -- stop exercising, and the psychological lift will disappear. The converse is also true: If you are used to regular physical activity, your mood will suffer if you take an exercise vacation.

Exercise tip 2: Choose activities that are moderately intense.

Aerobic exercise, such as walking and swimming, undoubtedly has mental health benefits, but you don't need to sweat strenuously to see results.

Exercise tip 3: Find exercises that are continuous and rhythmic (rather than intermittent).

Walking, swimming, dancing, stationery biking, and yoga are good choices.

Exercise tip 4: Be wary of competitive sports.

Exercise that pits people head-to-head with opponents may be too stressful, leading to a bad mood in the face of defeat. If you're the type whose competitive spirit may get the better of you, choose a physical activity that you enjoy and that allows you to de-stress.

Exercise tip 5: Add a mind-body element.

Activities such as yoga and tai chi rest your mind and pump up your energy. But if you don't want to do yoga or the

*Corresponding author: Charles Maack, US Too International Inc, 5003 Fairview Ave, Downers Grove, IL 60515, USA

Accepted: July 10, 2019

Published online: July 12, 2019

Citation: Maack C (2019) Exercise Considerations. J Cardiothorac Surg Ther 3(1):33-34 
like, you can add a meditative element to walking or swimming by repeating a mantra (a word or phrase) as you move.

Exercise tip 6: Start slowly, and don't overdo it. More isn't better.

Athletes who over-train find their moods drop rather than lift. You also risk injury and boredom if you push too hard, too fast, or too far.

Here are some examples of exercises addressed to the elderly, but if you are not yet in the "elderly" level, just ignore the word in the title [3].

Per Medical Oncologist Stephen B. Strum, MD, FACP, a specialist in research and treatment of advanced and recurring prostate cancer: Muscle loss is responsive to resistance exercises. As regards prostate cancer, we regularly read of the importance of exercise for everyone - not necessarily grueling exercise but at least moderate exercise. When prostate cancer patients have been treated with surgical removal of their prostate, radiation to the prostate gland and periphery, or are moved to androgen deprivation therapy (ADT) (wherein with the latter the resultant loss of testosterone and consequent weakening of muscle/bone), many experience fatigue/ tiredness/lethargy; this is particularly so for those whom regular exercise has not been in their life is routine. This issue addressed below, regarding fatigue for men moved to ADT and loss of testosterone, recognizes that men with lean mass (LM) found it easier to begin or continue an exercise routine. Men with various levels of fat mass (FM) - and likely not having an exercise routine - found moving to exercise difficult. This is further explained in this BJU International (BJUI) paper [4]. This paper, in addressing "lean mass" and "fat mass", would be applicable to any man experiencing any of the previous treatment procedures, and would apply to anyone with LM and FM issues. To slowly build up one's ability to reduce fatigue, improve muscle strength and bone support, and regain or improve vitality - and for those with fat mass to reduce that mass - it would be best to join a local physical fitness facility explaining your treatment issue(s) and requesting you be closely monitored as you embark on an appropriate exercise program. If living remote from such facilities, or preferring to work at your own improvement, then it would be best to develop a slow but steady exercise program. Just simple arm and leg exercises wherein you don't push yourself early on.

As recently as June 3, 2019, ASCO published a report wherein it was noted that "Exercise has repeatedly demonstrated [the ability to] alleviate many of the side effects, improve QOL, and decrease cancer recurrence and mortality...".

\section{References}

1. https://medlineplus.gov/ency/patientinstructions/000094.htm

2. https://www.womenfitness.net/top10/chest-pectoraldeveloping-exercises/

3. https://eldergym.com/exercises-for-the-elderly/

4. Robert U Newton, Emily Jeffery, Daniel A Galvão, et al. (2018) Body composition, fatigue and exercise in patients with prostate cancer undergoing androgen-deprivation therapy. Urological Oncology 122: 986-993.

DOI: $10.36959 / 582 / 417$ 